\title{
A short-term ionospheric forecasting empirical regional model (IFERM) to predict the critical frequency of the F2 layer during moderate, disturbed, and very disturbed geomagnetic conditions over the European area
}

\author{
M. Pietrella \\ Istituto Nazionale di Geofisica e Vulcanologia, via di Vigna Murata 605, 00143 Rome, Italy \\ Correspondence to: M. Pietrella (marco.pietrella@ingv.it)
}

Received: 6 July 2011 - Revised: 1 December 2011 - Accepted: 27 January 2012 - Published: 8 February 2012

\begin{abstract}
A short-term ionospheric forecasting empirical regional model (IFERM) has been developed to predict the state of the critical frequency of the F2 layer $(f o \mathrm{~F} 2)$ under different geomagnetic conditions.

IFERM is based on 13 short term ionospheric forecasting empirical local models (IFELM) developed to predict $f o \mathrm{~F} 2$ at 13 ionospheric observatories scattered around the European area. The forecasting procedures were developed by taking into account, hourly measurements of $f o \mathrm{~F} 2$, hourly quiettime reference values of $f o \mathrm{~F} 2(f o \mathrm{~F} 2 \mathrm{QT})$, and the hourly timeweighted accumulation series derived from the geomagnetic planetary index ap, $(\operatorname{ap}(\tau))$, for each observatory.

Under the assumption that the ionospheric disturbance in$\operatorname{dex} \ln (f o \mathrm{~F} 2 / f o \mathrm{~F} 2 \mathrm{QT})$ is correlated to the integrated geomagnetic disturbance index $\operatorname{ap}(\tau)$, a set of statistically significant regression coefficients were established for each observatory, over 12 months, over $24 \mathrm{~h}$, and under 3 different ranges of geomagnetic activity. This data was then used as input to compute short-term ionospheric forecasting of $f o \mathrm{~F} 2$ at the 13 local stations under consideration.
\end{abstract}

The empirical storm-time ionospheric correction model (STORM) was used to predict $f o \mathrm{~F} 2$ in two different ways: scaling both the hourly median prediction provided by IRI (STORM $f o F 2_{\mathrm{MED}, \mathrm{IRI}}$ model), and the $f o \mathrm{~F} 2_{\mathrm{QT}}$ values (STORM $\_f o \mathrm{~F} 2_{\mathrm{QT}}$ model) from each local station.

The comparison between the performance of STORM $f o$ F $2_{\text {MED,IRI, }}$ STORM $f o$ F2 $2_{\mathrm{QT}}$, IFELM, and the $f o \mathrm{~F} 2 \mathrm{QT}$ values, was made on the basis of root mean square deviation (r.m.s.) for a large number of periods characterized by moderate, disturbed, and very disturbed geomagnetic activity.

The results showed that the 13 IFELM perform much better than STORM $f o F 2_{\mathrm{MED}, \mathrm{IRI}}$ and $\mathrm{STORM}_{-} f o \mathrm{~F} 22_{\mathrm{QT}}$ espe- cially in the eastern part of the European area during the summer months (May, June, July, and August) and equinoctial months (March, April, September, and October) under disturbed and very disturbed geomagnetic conditions, respectively. The performance of IFELM is also very good in the western and central part of the Europe during the summer months under disturbed geomagnetic conditions. STORM $_{f} f \circ 2_{\text {MED,IRI }}$ performs particularly well in central Europe during the equinoctial months under moderate geomagnetic conditions and during the summer months under very disturbed geomagnetic conditions.

The forecasting maps generated by IFERM on the basis of the results provided by the 13 IFELM, show very large areas located at middle-high and high latitudes where the $f o \mathrm{~F} 2$ predictions quite faithfully match the $f o \mathrm{~F} 2$ measurements, and consequently IFERM can be used for generating short-term forecasting maps of $f o \mathrm{~F} 2$ (up to $3 \mathrm{~h}$ ahead) over the European area.

Keywords. Ionosphere (Ionosphere-magnetosphere interactions; Ionospheric disturbances; Modeling and forecasting)

\section{Introduction}

A large number of global (Jones and Gallet, 1962; Comite Consultatif International des Radio Communications (CCIR), 1991; International Telecommunication Union (ITU), 1997) and regional models (Bradley, 1999; Hanbaba, 1999) have been developed over the years to predict the monthly medians of the key ionospheric characteristics of the F2 layer, including its critical frequency, $f o \mathrm{~F} 2$, and obliquity factor for a distance of $3000 \mathrm{~km}, M(3000) F 2$. Other long term prediction models like the IPS-ASAPS and ICEPAC are 
also able to predict sky wave communication conditions in the HF radio spectrum. The IPS-ASAPS (Advanced Stand Alone Prediction System) is based on ITU-R/CCIR models (Rec. ITU-R P.533-8, Rec. ITU-R P.372-8 and CCIR Reports 322) and on an ionospheric model developed by the IPS Radio and Space Services of the Australian Department of Industry, Tourism and Resources (IPS-Radio and Space Services, undated). The ICEPAC (Ionospheric Communications Enhanced Profile Analysis and Circuit) is a full system performance model for HF radio communication circuits (Stewart, undated). As recent studies have shown, ASAPS and ICEPAC provide good guidelines for the choice of maximum usable frequencies (MUF) for use in radio communications under "quiet" ionospheric conditions (Zolesi et al., 2008). The situation is completely different under "disturbed" ionospheric conditions related to geomagnetic storm events. A large number of studies on ionospheric storms have been carried out in the past. Several experimental and theoretical studies have defined a phenomenological scenario of the ionospheric response to geomagnetic storms (see reviews by: Prölss, 1995, 1997; Fuller-Rowell et al., 1997; Buonsanto, 1999). It is well known that solar wind particles of increased speed and/or density, caused by solar disturbances like coronal mass ejections, captured by the Earth's magnetosphere, cause changes in the Earth's magnetic field and result in the so called geomagnetic storms. During these events large energy inputs, in the form of enhanced electric fields, currents, and energetic particle precipitation, cause a noticeable joule heating of atmospheric gases. The resulting expansion of the thermosphere at high latitudes alters the composition of neutral air, especially atomic oxygen [O], molecular nitrogen $\left[\mathrm{N}_{2}\right]$, and molecular oxygen $\left[\mathrm{O}_{2}\right]$. The vertical motion of these species can result in a decrease in the $[\mathrm{O}] /\left[\mathrm{N}_{2}\right]$ and $[\mathrm{O}] /\left[\mathrm{O}_{2}\right]$ ratios (Rishbeth et al., 1987), which strongly influences the electron density of the F2 region. When the heating events are impulsive, the expansion of the atmosphere also produces winds that transport the composition changes from higher to lower latitudes manifesting themselves as motions of the neutral atmosphere on a large scale (Richmond and Matsushita, 1975; Roble et al., 1978; Burns and Killen, 1992; Hocke and Schlegel, 1996). These motions, more properly called gravity waves (GW), have their origin in the auroral zones. Testud (1970) and Titheridge (1971) demonstrated that GW are observed much more frequently when geomagnetic activity is particularly marked, i.e. in the course of geomagnetic storm events. Observations of the oscillations of electron density suggest that GW activity occurs in the F-region of the ionosphere (Pietrella et al., 1997). GW activity generates wavelike motions called travelling ionospheric disturbances (TIDs), which can play an important role in changing ionization, making HF communications difficult. Therefore, during geomagnetic storm events important changes in electron density content can alter day-to-day F-region ionospheric variability. Ionization density can either increase or decrease during disturbed con- ditions. These changes are denoted as negative or positive ionospheric storms, according to whether $f_{o} \mathrm{~F} 2$ is below or above its "quiet value", respectively.

The long term prediction models for $f o \mathrm{~F} 2$ are not able to provide reliable forecasts during ionospheric storms, when considerable reductions of $f o \mathrm{~F} 2$ can occur. During these events, rather than the monthly median models, like ASAPS and ICEPAC, nowcasting models are more appropriate for forecasting depletion of MUF (Pietrella et al., 2009), which represents a serious drawback for maintaining efficient management of HF radio communications. As a result, there is a need to develop nowcasting models (AraujoPradere et al., 2002; Zolesi et al., 2004; Pietrella and Perrone, 2005) and short-term forecasting models (Cander et al., 1998; Muhtarov and Kutiev, 1999; Oyeyemi et al., 2005) for the prediction of $f \circ \mathrm{F} 2$ for a few hours ahead. This would provide $\mathrm{HF}$ operators with real-time or quasi-real-time assistance in choosing optimal frequencies for radio links, even in the case of a strongly disturbed ionosphere. The problem of forecasting the ionospheric disturbances associated with geomagnetic storms has already been examined in the past. Many geomagnetic indices were studied in order to establish which of them could best forecast the ionospheric response to geomagnetic storms (Mendillo, 1973). Changes in $f_{o} \mathrm{~F} 2$ measurements, with respect to estimated quiet-time values, were used as an ionospheric disturbance index (IDI) for defining a predictive scheme for $f \circ \mathrm{F} 2$ (Wrenn et al., 1987; Wrenn and Rodger, 1989). Ionospheric disturbances during extreme geomagnetic storms were studied with the aim of developing local forecasting models (Cander and Mihajlovic, 1998). More recently a short term ionospheric forecasting empirical local model to predict $f o \mathrm{~F} 2$ over Rome during significant geomagnetic storm events was developed by Pietrella and Perrone (2008).

Inspired by the latter, an ionospheric forecasting empirical regional model for the prediction of $f o \mathrm{~F} 2$, based on a certain number $N$ of local models, has been developed.

During a geomagnetic storm, the level of geomagnetic activity changes from place to place. Consequently, since the effects of the ionospheric storm correspond closely to the level of geomagnetic activity, the most important factor for discriminating the diverse effects that a storm has on the behaviour of the ionospheric F-region is the difference in latitude.

Therefore the idea forming the basis of this new work is that, given a certain number $N$ of local models for the prediction of $f o \mathrm{~F} 2$ suitably dispersed in latitude, and each of them able to adequately "capture" the local effects of a storm on $f o \mathrm{~F} 2$, then using these simultaneously makes it possible to "reproduce" the effects that a storm has on the behaviour of the F-region on a spatial scale larger than the local one. In other words, the $N$ local models, taken together, may be appropriately used to produce forecasting maps of $f o \mathrm{~F} 2$ during geomagnetic storm events over the area including the $N$ models. 
Table 1. List of ionospheric stations used for the development of IFERM: the range of years considered to obtain the set of regression coefficients (column A) and the range of years taken into account for testing (column B) are shown for each ionospheric observatory.

\begin{tabular}{lcccc}
\hline Station & Latitude & Longitude & $\mathrm{A}$ & $\mathrm{B}$ \\
\hline Dourbes & $50^{\circ} \cdot 1^{\prime} \mathrm{N}$ & $4^{\circ} \cdot 6^{\prime} \mathrm{E}$ & $1957-1987$ & $1988-1997$ \\
Juliusruh & $54^{\circ} \cdot 6^{\prime} \mathrm{N}$ & $13^{\circ} \cdot 4^{\prime} \mathrm{E}$ & $1957-1990$ & $1991-2003$ \\
Kaliningrad & $54^{\circ} \cdot 7^{\prime} \mathrm{N}$ & $20^{\circ} \cdot 6^{\prime} \mathrm{E}$ & $1964-1986$ & $1987-1994$ \\
Kiruna & $67^{\circ} \cdot 8^{\prime} \mathrm{N}$ & $20^{\circ} \cdot 4^{\prime} \mathrm{E}$ & $1957-1985$ & $1986-1998$ \\
Lannion & $48^{\circ} \cdot 1^{\prime} \mathrm{N}$ & $2^{\circ} .^{\prime} \mathrm{E}$ & $1961-1987$ & $1988-1997$ \\
Lyckesele & $64^{\circ} \cdot 6^{\prime} \mathrm{N}$ & $18^{\circ} \cdot 8^{\prime} \mathrm{E}$ & $1957-1987$ & $1988-1998$ \\
Poitiers & $46^{\circ} \cdot 6^{\prime} \mathrm{N}$ & $0^{\circ} \cdot 3^{\prime} \mathrm{E}$ & $1957-1988$ & $1989-1998$ \\
Pruhonice & $50^{\circ} \cdot 0^{\prime} \mathrm{N}$ & $14^{\circ} \cdot 6^{\prime} \mathrm{E}$ & $1958-1984$ & $1985-1999$ \\
Rome & $41^{\circ} \cdot 9^{\prime} \mathrm{N}$ & $12^{\circ} \cdot 5^{\prime} \mathrm{E}$ & $1957-1990$ & $1991-2000$ \\
Slough & $51^{\circ} \cdot 5^{\prime} \mathrm{N}$ & $-0^{\circ} \cdot 6^{\prime} \mathrm{W}$ & $1957-1989$ & $1990-2003$ \\
Sodankyla & $67^{\circ} \cdot 4^{\prime} \mathrm{N}$ & $26^{\circ} \cdot 6^{\prime} \mathrm{E}$ & $1957-1987$ & $1988-1997$ \\
Tortosa & $40^{\circ} \cdot 8^{\prime} \mathrm{N}$ & $0^{\circ} \cdot 5^{\prime} \mathrm{E}$ & $1955-1986$ & $1987-2001$ \\
Uppsala & $59^{\circ} \cdot 8^{\prime} \mathrm{N}$ & $17^{\circ} \cdot 6^{\prime} \mathrm{E}$ & $1957-1988$ & $1989-1998$ \\
\hline
\end{tabular}

With these considerations in mind, 13 ionospheric forecasting empirical local models (IFELM), for predicting the state of the critical frequency of the F2 layer, $f o \mathrm{~F} 2$, at 13 ionospheric observatories scattered over the European area (Tortosa, Rome, Poitiers, Lannion, Pruhonice, Dourbes, Slough, Kaliningrad, Juliusruh, Uppsala, Lyckesele, Sodankyla, and Kiruna) (Fig. 1), were developed with the assumption that there is an empirical relationship between IDI and geomagnetic activity.

Since geomagnetic activity can be described with indices that can be predicted for a few hours in advance, the 13 IFELM could be used for the short term ionospheric forecasting of $f o \mathrm{~F} 2$ during non quiet geomagnetic conditions. However, there are two very important factors: the choice of the most representative index of geomagnetic activity and the definition of the reference quiet-time values. Some studies have shown that the extent of significant storm effects depends more on the average value of the geomagnetic index ap rather than the peak value. This means that the magnitude of main phase $f_{o} \mathrm{~F} 2$ deviations could be better described using an integration of ap that takes into account the recent history of geomagnetic activity (Wrenn et al., 1987). The geomagnetic index used in this study is the $\operatorname{ap}(\tau)$ index introduced by Wrenn (1987). It reflects an integration of geomagnetic activity over a number of 3-h intervals, giving more weight to the recent past and less to measurements from earlier periods. Studies concerning the correlation coefficients from linear fitting of the IDI and geomagnetic activity as a function of $\tau$, have shown that for the southern high latitude ionosphere the best fit is obtained for $\tau=0.80$ (Perrone et al., 2001) and for $\tau=0.75$ (Wrenn et al., 1987) while for the middlehigh latitude ionosphere the best fit was found for $\tau=0.815$ (Wrenn and Rodger, 1989).

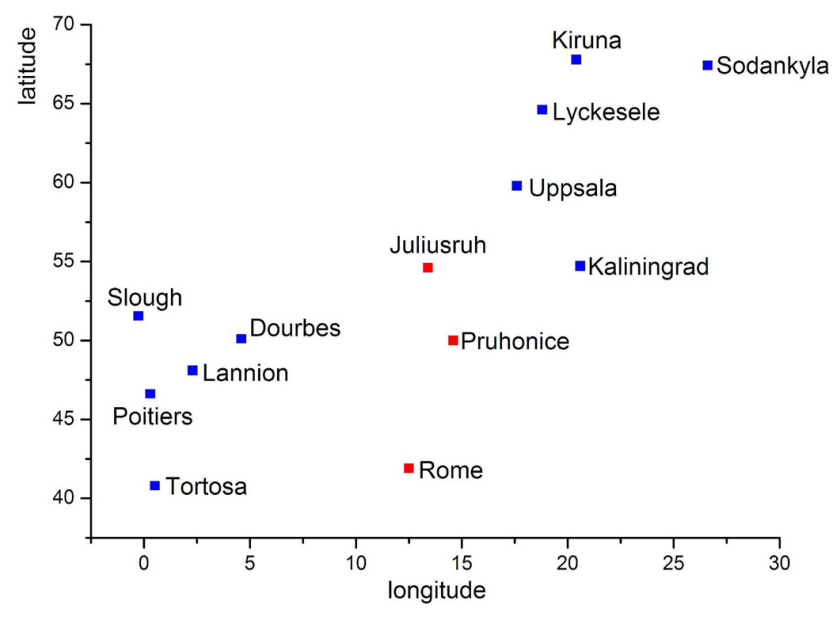

Fig. 1. Geographic area showing the 13 ionospheric observatories for which the local forecasting models were developed. The blue dots mark the western and eastern parts of the area under consideration; the red dots mark the central part of Europe.

The ionospheric observatories utilized to develop the 13 IFELM, are located at middle, middle-high, and high latitudes (Table 1) and so a preliminary study was conducted to investigate which $\tau$ value is most suitable for each station. Taking into account the previous results, the values $\tau=0.7, \tau=0.8$, and $\tau=0.9$ were considered and the best fit was found for two different values of $\tau$ : $\tau=0.8$ for the three stations located at higher latitudes (Lyckesele, Sodankyla, and Kiruna); $\tau=0.9$ for the stations located at middle and middle-high latitudes (Tortosa, Rome, Poitiers, Lannion, Pruhonice, Dourbes, Slough, Kaliningrad, Juliusruh, and Uppsala).

In this study it is also of crucial importance to define the representative $f o \mathrm{~F} 2$ values for the undisturbed ionosphere. Although the monthly median values of $f o \mathrm{~F} 2$ are usually considered as representative of a quiet state of the ionosphere (Cander and Mihajlovic, 1998), in reality it is very difficult to define a parameter that accurately represents a "quiet" ionosphere (Kouris and Fotiadis, 2002). A review of literature in this field shows that the monthly median values of $f o \mathrm{~F} 2$ give rise to many artificial effects (Kozin et al., 1995). They are inadequate to describe "quiet" ionospheric behaviour and alternative quiet-time reference values are required (Wrenn et al., 1987). In fact, many attempts have been made in the past to define a suitable index for characterizing the "quiet" state of the ionosphere (Wrenn et al., 1987; Cooper et al., 1993; Zolesi and Cander, 1998; Belehaki et al., 2000).

In order to develop the forecasting procedure, hourly quiet-time values of $f o \mathrm{~F} 2, f o \mathrm{~F} 2 \mathrm{QT}$, estimated for each individual station following a procedure similar to that devised by Wrenn et al. (1987), the hourly measurements of foF2 from each ionospheric observatory, and the hourly timeweighted accumulation series derived from the geomagnetic planetary index ap, ap $(\tau)$, to take into account the recent 
history of geomagnetic activity (Wrenn, 1987), were considered over the years as shown in column A of Table 1 (solar cycles 19, 20,21, 22, and 23).

Based on previous studies (Perrone et al., 2001, and references therein; Wrenn et al., 1987), all data considered was selected on the basis of three different ranges of geomagnetic activity: moderate $7<\operatorname{ap}(\tau=0.8 / \tau=0.9) \leq 20$; disturbed $20<\operatorname{ap}(\tau=0.8 / \tau=0.9) \leq 32$; very disturbed $\operatorname{ap}(\tau=$ $0.8 / \tau=0.9)>32$ excluding from the entire data set all the periods occurring over the years shown in column B of Table 1, which were subsequently used to test IFELM performance.

Since the 13 IFELM, taken together, can be considered as a single short term ionospheric forecasting empirical regional model, hereafter they are also referred to simply as IFERM.

For each range of geomagnetic activity selected and for each month, a statistically significant linear correlation was found between $\ln \left(f o \mathrm{~F} 2 / f o \mathrm{~F} 2{ }_{\mathrm{QT}}\right)$ and $\operatorname{ap}(\tau=0.8 / \tau=0.9)$. The coefficients of linear regression obtained for different months, hours, and ranges of geomagnetic activity, and the predicted $\operatorname{ap}(\tau=0.8 / \tau=0.9)$ values, were utilized as input to calculate a short-term ionospheric forecast for $f o \mathrm{~F} 2$. STORM is an empirical storm-time ionospheric correction model developed using data from 43 storms that occurred in the 1980s (Araujo-Pradere et al., 2002). This model was included in the new International Reference Ionosphere (Bilitza, 2001). It provides an estimate of the expected change in the ionosphere during a period of increased geomagnetic activity. STORM provides as output the correction factors to "adjust" the quiet-time values of $f o \mathrm{~F} 2$. A few comparisons between the performance of IFERM, STORM, and the $f o \mathrm{~F} 2 \mathrm{QT}$ values are shown in terms of r.m.s. error for very disturbed geomagnetic conditions.

Some comparisons between the maps based on $f o \mathrm{~F} 2$ measurements and the maps generated from IFERM's predictions, are also shown for a few days characterized by moderate, disturbed, and very disturbed geomagnetic activity.

The data analysis and model description are described in Sect. 2. The testing procedure, the comparisons and the results are presented in Sect. 3. Concluding remarks on the IFERM approach are summarised and possible future developments are outlined in Sect. 4.

\section{Data analysis and model description}

The IFERM (ionospheric forecasting empirical regional model) was developed using $f o \mathrm{~F} 2$ measurements taken at 13 ionospheric observatories over an extended period of years (Table 1, column A).

The other two parameters utilized for data analysis were the hourly time-weighted accumulation series derived from the geomagnetic planetary index ap, $(\operatorname{ap}(\tau))$, and the hourly quiet-time reference values of $f o \mathrm{~F} 2(f o \mathrm{~F} 2 \mathrm{QT})$.
The $f o \mathrm{~F} 2 \mathrm{QT}$ were calculated for each specific ionospheric observatory adopting the procedure described in detail in Pietrella and Perrone (2008), following a method analogous to that elaborated by Wrenn (1987).

\subsection{Forecasting procedure and STORM model}

For any hour of any day of any month over the years reported in the column A of Table 1 , the ratios $\ln (f o \mathrm{~F} 2 / f o \mathrm{~F} 2 \mathrm{QT})$ were calculated and binned in terms of three different ranges of geomagnetic activity: $7<\operatorname{ap}(\tau=0.8) \leq 20,20<\operatorname{ap}(\tau=$ $0.8) \leq 32$, and $\operatorname{ap}(\tau=0.8)>32$ for the stations in Lyckesele, Sodankyla, and Kiruna ( $\alpha$ group); $7<\operatorname{ap}(\tau=0.9) \leq 20$, $20<\operatorname{ap}(\tau=0.9) \leq 32$, and $\operatorname{ap}(\tau=0.9)>32$ for the stations in Tortosa, Rome, Poitiers, Lannion, Pruhonice, Dourbes, Slough, Kaliningrad, Juliusruh, and Uppsala ( $\beta$ group) in order to select data relative to various disturbed geomagnetic conditions for each ionospheric observatory.

Each bin included a large set of hourly time-series of $\ln (f o \mathrm{~F} 2 / f o \mathrm{~F} 2 \mathrm{QT})-\operatorname{ap}(\tau=0.8)$ for $\alpha$ group, and $\ln (f o \mathrm{~F} 2 / f o \mathrm{~F} 2 \mathrm{QT})-\operatorname{ap}(\tau=0.9)$ for $\beta$ group on which a linear regression analysis was performed.

On the basis of the procedure described above, 864 $(24 \mathrm{~h} \times 3$ ranges of geomagnetic activity $\times 12$ months) pairs of regression coefficients were calculated for each single observatory assuming the following statistical model:

$\ln \frac{f o \mathrm{~F} 2}{f o \mathrm{~F} 2}=A+B \cdot \operatorname{ap}(\tau)$

where $\tau=0.8$ and $\tau=0.9$ for the stations of the $\alpha$ and $\beta$ groups, respectively.

The numerical coefficients $A$ and $B$ were calculated by means of the least squares method. Each pair of coefficients represents a potential model to use for short-term forecasting of $f o \mathrm{~F} 2$.

A Fisher's test with a confidence level $=95 \%$ was performed for each model to check its statistical significance. Another Fisher's test was performed on any discarded coefficients to establish if these coefficients could be accepted with a confidence level $=90 \%$. In this way, it was possible to select $11232(864 \times 13)$ pairs of statistically significant regression coefficients. These are referred to hereafter as $\left(A_{\mathrm{ls}, \mathrm{h}, \mathrm{m}, \mathrm{rga}}, B_{\mathrm{ls}, \mathrm{h}, \mathrm{m}, \mathrm{rga}}\right)$, indicating that they depend on the local station, hour, month, and range of geomagnetic activity. The 11232 pairs of coefficients $\left(A_{\mathrm{ls}, \mathrm{h}, \mathrm{m}, \mathrm{rga}}, B_{\mathrm{ls}, \mathrm{h}, \mathrm{m}, \mathrm{rga}}\right)$ collectively constitute the IFERM model and they are the input to the following prediction algorithm

$f o \mathrm{~F} 2_{\text {predicted,ls, h, m,rga }}=f o \mathrm{~F} 2_{\mathrm{QT}} \cdot \exp ^{A_{\mathrm{ls}, \mathrm{h}, \mathrm{m}, \mathrm{rga}}+B_{\mathrm{ls}, \mathrm{h}, \mathrm{m}, \mathrm{rga}} \cdot \mathrm{ap}(\tau)}(2)$

setting $\tau=0.8$ and $\tau=0.9$ for the stations belonging to $\alpha$ group and $\beta$ group, respectively.

The pairs of regression coefficients $\left(A_{1 \mathrm{~s}, \mathrm{~h}, \mathrm{~m}, \mathrm{rga}}, B_{\mathrm{ls}, \mathrm{h}, \mathrm{m}, \mathrm{rga}}\right)$ were utilized in Eq. (2) to obtain an ionospheric forecasting of $f_{o} \mathrm{~F} 2$ at the 13 ionospheric observatories over moderate $(7<\operatorname{ap}(\tau=0.8 / \tau=0.9 \leq 20)$, disturbed $(20<\operatorname{ap}(\tau=$ 
$0.8 / \tau=0.9) \leq 32)$, and very disturbed $(\operatorname{ap}(\tau=0.8 / \tau=$ $0.9>32$ ) periods selected over the years and reported in column B of Table 1.

The predictions of $f o \mathrm{~F} 2$ provided by the 13 IFELM for a given epoch (hour, day, month, year) represent the IFERM prediction for that epoch.

The global model STORM, implemented in the global IRI model (Bilitza and Reinisch, 2008), provides a correction factor for each hour $h$, depending on the geomagnetic latitude $\left(\mathrm{CF}_{\lambda^{\circ}, h}\right)$, and this is used to "correct" the quiet-time value of $f o \mathrm{~F} 2$. Therefore, for a comparison with the predictions provided by the 13 IFELM , the correction factors were calculated for all $24 \mathrm{~h}$ of the day for all the ionospheric observatories under consideration. Since STORM can scale the output of any quiet-time ionospheric model, the 24 hourly median measurements of $f o \mathrm{~F} 2$ predicted by IRI, ( $f o \mathrm{~F} 2 \mathrm{MED,IRI})$, as well as the 24 hourly reference quiet time values calculated for each ionospheric observatory $\left(f o \mathrm{~F} 22_{\mathrm{QT}}\right)$, were considered as the quiet-time ionospheric levels of $f \circ \mathrm{F} 2$. Therefore, the prediction at a given hour, $h$, was calculated in two different cases by the Eqs. (3)-(4).

STORM $_{f} f o 2_{\mathrm{MED}, \mathrm{IRI}, \mathrm{h}}=\mathrm{CF}_{\lambda^{\circ}, h} \cdot f o \mathrm{~F}_{\mathrm{MED}, \mathrm{IRI}, \mathrm{h}}$

$\mathrm{STORM}_{f} f o \mathrm{~F} 2_{\mathrm{QT}, \mathrm{h}}=\mathrm{CF}_{\lambda^{\circ}, h} \cdot f o \mathrm{~F} 2_{\mathrm{QT}, \mathrm{h}}$

\section{Testing procedure comparisons and results}

The performance of each local model calculated in terms of root mean square deviation (r.m.s.) was compared with the performance of the STORM model obtained scaling both the hourly median prediction provided by IRI

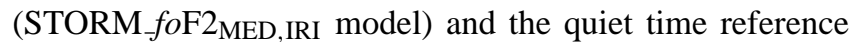
values of $f o \mathrm{~F} 2$ from each local station $\left(\mathrm{STORM}_{-} f o \mathrm{~F} 22_{\mathrm{QT}}\right.$ model). For a further comparison the predictions of $f o \mathrm{~F} 2$ provided by each local model were also compared with the hourly series of $f o \mathrm{~F} 2 \mathrm{QT}$.

All the periods characterised by moderate, disturbed, and very disturbed geomagnetic conditions, were selected for each ionospheric observatory over the years reported in the column B of Table 1, and then grouped together. Subsequently, these data sets were binned by single month, and performance was calculated for all the months in terms of global r.m.s. error under moderate, disturbed, and very disturbed geomagnetic activity.

As an example, Table 2 shows the comparisons in terms of global r.m.s. error between some IFELM, $\mathrm{STORM}_{-} f o \mathrm{~F} 2_{\mathrm{MED}, \mathrm{IRI}}$, and $\mathrm{STORM}_{-} f o \mathrm{~F} 2_{\mathrm{QT}}$ models, and $f o \mathrm{~F} 2 \mathrm{QT}$ under very disturbed geomagnetic conditions.

Table 3 indicates the models that produce the smallest global r.m.s. error, i.e. the best performance, for each station, month, and all the three selected ranges of geomagnetic activity. This table clearly shows that in some cases, STORM $f o$ F $2_{\text {MED,IRI }}$ performs better than the local model.
When this happens, it is assumed that the local model can not be used for prediction of $f o \mathrm{~F} 2$ and it is discarded.

This is not a serious problem because with 13 IFELM available, there are always a certain number $N$ of IFELM operating simultaneously (see Table 4, last column) making it possible to forecast $f o \mathrm{~F} 2$ over the area in question.

The cases in which it is possible to consider the different IFELM simultaneously operative for forecasting $f o \mathrm{~F} 2$ over the European area are shown in Table 4 for each month and under different geomagnetic conditions.

Figures 2, 3, and 4 show comparisons between the maps based on $f o \mathrm{~F} 2$ measurements (Figs. 2a, 3a, 4a) and the foF 2 forecasting maps (Figs. 2b, 3b, 4b) obtained using the IFERM model for three different epochs characterized by moderate, disturbed, and very disturbed geomagnetic activity.

\section{Discussion of the results and future developments}

A careful analysis of the performance of the various models reported in Table 3, leads to the following conclusions.

As regards the western part of the European area under consideration, (including the stations of Tortosa, Poitiers, Lannion, Dourbes, and Slough), extending in latitude from $40^{\circ} .8^{\prime} \mathrm{N}$ to $51^{\circ} .5^{\prime} \mathrm{N}$ and in longitude from $-0^{\circ} .6^{\prime} \mathrm{W}$ to $4^{\circ} .6^{\prime} \mathrm{E}$, the IFELM perform far better than

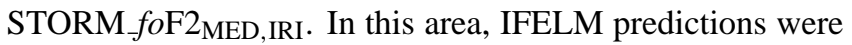
better in $71 \%$ of cases, while the STORM $f o$ F 2 MED, IRI predictions were better in only $23 \%$ of the cases analysed.

In the winter months the performance of IFELM is far

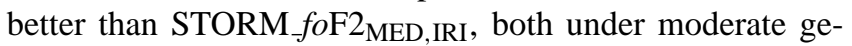
omagnetic activity (IFELM predictions were better in $70 \%$ of cases, while STORM $f o F 2_{\mathrm{MED} \text {,IRI }}$ predictions were better in $10 \%$ of the cases analysed) and under very disturbed geomagnetic activity (IFELM predictions were better in $74 \%$ of cases, while STORM $f o F 2_{\mathrm{MED} \text {,IRI }}$ predictions were better in $5 \%$ of the cases analysed). Under disturbed geomagnetic conditions, the performance of IFELM is slightly better than STORM $f o F 2_{\text {MED,IRI, providing more accurate predictions }}$

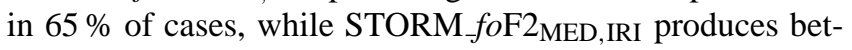
ter predictions in $30 \%$ of the cases analysed.

In the equinoctial months it emerges that under moderate geomagnetic activity, the 13 IFELM and the

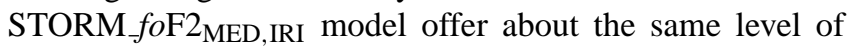
performance (IFELM predictions were better in $50 \%$ of cases, while STORM $f o \mathrm{~F} 2_{\mathrm{MED}, I R I}$ predictions were better in $45 \%$ of the cases analysed).

IFELM perform much better than STORM $f o$ F 2 MED,IRI under disturbed geomagnetic activity (IFELM predictions were better in $85 \%$ of cases, while STORM $f o$ F2 MED,IRI predictions were better in $15 \%$ of the cases analysed). IFELM perform better than STORM $f o$ F $2_{\text {MED, IRI }}$ under very disturbed geomagnetic activity (IFELM predictions were better 
Table 2. Performance in terms of global r.m.s. error for very disturbed geomagnetic activity $(\operatorname{ap}(\tau=0.8 / \tau=0.9)>32)$ for some stations located in the western (Lannion and Slough), central (Rome and Juliusruh), and eastern (Sodankyla and Kiruna) part of the area under consideration. The numbers in black bold indicate the number of samples considered for the calculation of the global r.m.s. error. The cases in which the IFELM, and STORM $f o F 2_{\mathrm{MED}, \mathrm{IRI}}$, provide the best performance are reported in blue and green, respectively.

\begin{tabular}{|c|c|c|c|c|}
\hline & IFELM & $\mathrm{STORM}_{-} f o \mathrm{~F} 2 \mathrm{MED}, \mathrm{IRI}$ & $\mathrm{STORM}_{-} f o \mathrm{~F} 2 \mathrm{QT}$ & foF $2 Q T$ \\
\hline \multicolumn{5}{|l|}{ Lannion } \\
\hline April; $N=379$ & 1.12 & 1.40 & 1.50 & 2.33 \\
\hline June; $N=357$ & 0.98 & 1.15 & 1.31 & 2.69 \\
\hline November; $N=\mathbf{2 2 2}$ & 1.63 & 2.60 & 2.10 & 2.17 \\
\hline \multicolumn{5}{|l|}{ Slough } \\
\hline August; $N=\mathbf{4 4 3}$ & 1.22 & 1.18 & 1.68 & 2.70 \\
\hline September; $N=\mathbf{4 6 2}$ & 1.23 & 1.36 & 1.50 & 2.29 \\
\hline December; $N=\mathbf{5 5}$ & 0.94 & 1.66 & 1.42 & 1.41 \\
\hline \multicolumn{5}{|l|}{ Rome } \\
\hline January; $N=14$ & 0.66 & 0.69 & 0.80 & 0.87 \\
\hline May; $N=371$ & 1.17 & 1.07 & 1.21 & 1.54 \\
\hline October; $N=\mathbf{4 0 6}$ & 1.90 & 2.03 & 2.88 & 2.72 \\
\hline \multicolumn{5}{|l|}{ Juliusruh } \\
\hline $\operatorname{March} ; N=328$ & 1.41 & 1.37 & 1.57 & 2.77 \\
\hline July; $N=196$ & 0.94 & 0.86 & 1.00 & 2.20 \\
\hline November; $N=\mathbf{5 7 5}$ & 1.37 & 1.52 & 1.93 & 2.29 \\
\hline \multicolumn{5}{|l|}{ Sodankyla } \\
\hline April; $N=63$ & 1.00 & 1.28 & 1.85 & 2.72 \\
\hline July; $N=\mathbf{5 2}$ & 0.79 & 0.68 & 0.81 & 1.51 \\
\hline December; $\boldsymbol{N}=\mathbf{4 0}$ & 1.70 & 2.31 & 2.70 & 3.01 \\
\hline \multicolumn{5}{|l|}{ Kiruna } \\
\hline January; $N=\mathbf{2 2}$ & 0.48 & 1.07 & 0.89 & 1.10 \\
\hline May; $N=74$ & 0.79 & 1.01 & 1.27 & 1.96 \\
\hline October; $N=146$ & 1.60 & 1.76 & 2.82 & 3.72 \\
\hline
\end{tabular}

in $65 \%$ of cases, while $\mathrm{STORM}_{-} f \circ 2_{\mathrm{MED}, \mathrm{IRI}}$ predictions were better in $35 \%$ of the cases investigated).

In the summer months it is seen that IFELM perfor-

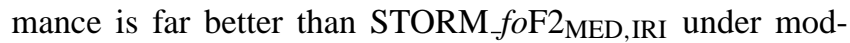
erate geomagnetic activity (IFELM predictions were better in $75 \%$ of cases, while STORM_foF $2_{\text {MED,IRI predic- }}$ tions were better in $15 \%$ of the cases analysed) and disturbed geomagnetic activity (IFELM predictions were better in $95 \%$ of cases, while STORM $f o$ F $2_{\text {MED,IRI }}$ predictions were better in $5 \%$ of the cases analysed). Under very disturbed geomagnetic conditions, IFELM perform slightly better than $\mathrm{STORM}_{-} f o \mathrm{~F} 2_{\mathrm{MED}, \text { IRI }}$ (IFELM predictions were better in $60 \%$ of cases, while STORM $f o F 2_{\text {MED,IRI predictions }}$ were better in $40 \%$ of the cases analysed).

In the central part of the area (including the stations of Rome, Pruhonice, and Juliusruh), extending in latitude from $41^{\circ} .9^{\prime} \mathrm{N}$ to $54^{\circ} .6^{\prime} \mathrm{N}$ and in longitude from $12^{\circ} .5^{\prime} \mathrm{E}$ to $14^{\circ} .6^{\prime} \mathrm{E}, \mathrm{STORM}_{-} f \circ 2_{\mathrm{MED}, \mathrm{IRI}}$ performs better than IFELM.

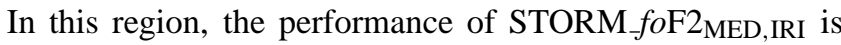
better in $55 \%$ of cases, while IFELM performance is better in only $38 \%$ of the cases analysed.

In the winter months, the performance of STORM $f o$ F $2_{\text {MED,IRI }}$ is always considerably better than IFELM under moderate geomagnetic conditions (IFELM predictions were better in $17 \%$ of cases, while $\mathrm{STORM}_{f} f \circ 2_{\mathrm{MED} \text {,IRI }}$ predictions were better in $67 \%$ of the cases analysed), and under disturbed geomagnetic conditions (IFELM predictions were better in $8 \%$ of cases, while $\mathrm{STORM}_{f} f \circ 2_{\mathrm{MED}, \text { IRI }}$ predictions were better in $67 \%$ of the cases analysed). Under very disturbed geomagnetic conditions, IFELM perform slightly better than STORM $f o F 2_{\text {MED,IRI }}$ (IFELM predictions were better in $55 \%$ of cases, while STORM $f o \mathrm{~F} 2 \mathrm{MED}$, IRI predictions were better in $27 \%$ of the cases analysed). 


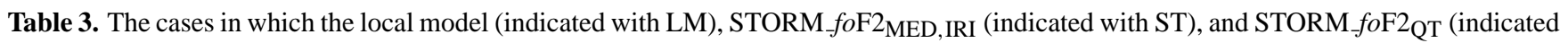
with ST_QRV) models, and the quiet reference values of foF2 (indicated with QRV) provide the best performance in terms of global r.m.s. error, under moderate $(\mathrm{m})$, disturbed $(\mathrm{d})$, and very disturbed (vd) geomagnetic activity are shown in blue, green, red, and purple, respectively, for all the months and for all the stations. The symbol *** indicates that no data was available to calculate the global r.m.s. error.

\begin{tabular}{|c|c|c|c|c|c|c|c|c|c|c|c|c|c|}
\hline Month & Tor & Poi & Lan & Dou & Slo & Rom & Pru & Jul & $\mathrm{Kal}$ & Upp & Lyc & Sod & Kir \\
\hline Jan (m) & LM & LM & LM & ST & LM & ST & ST & LM & LM & LM & ST & LM & LM \\
\hline Jan (d) & LM & LM & LM & ST & LM & ST_QRV & ST & LM & ST & LM & ST & LM & LM \\
\hline Jan (vd) & QRV & $* * *$ & LM & $\mathrm{LM}$ & ST & LM & LM & LM & LM & LM & ST & LM & LM \\
\hline $\mathrm{Feb}(\mathrm{m})$ & ST & QRV & QRV & QRV & LM & ST & ST & ST & QRV & LM & ST & ST & LM \\
\hline Feb (d) & ST & LM & LM & LM & LM & ST & ST & ST & LM & LM & LM & LM & LM \\
\hline Feb (vd) & QRV & LM & LM & LM & LM & ST & LM & ST & LM & LM & ST & LM & ST \\
\hline $\operatorname{Mar}(\mathrm{m})$ & LM & ST_QRV & LM & LM & LM & LM & ST & ST & LM & $\mathrm{LM}$ & ST & LM & ST \\
\hline $\operatorname{Mar}(d)$ & LM & LM & LM & ST & LM & ST & ST & ST & ST & ST & LM & LM & ST \\
\hline Mar (vd) & $\mathrm{ST}$ & LM & ST & ST & ST & LM & ST & ST & ST & ST & LM & LM & LM \\
\hline $\operatorname{Apr}(\mathrm{m})$ & LM & ST & LM & ST & ST & ST & ST & ST & ST & ST & ST & ST & LM \\
\hline Apr (d) & LM & LM & $\mathrm{ST}$ & ST & LM & ST & ST & ST & LM & LM & $\mathrm{ST}$ & $\mathrm{ST}$ & ST \\
\hline Apr (vd) & ST & LM & LM & LM & LM & ST & ST & ST & LM & LM & LM & LM & LM \\
\hline May (m) & LMST & ST & LM & ST & LM & ST & LM & LM & LM & LM & LM & ST & ST \\
\hline May (d) & LM & ST & LM & LM & LM & ST & LM & LM & LM & LM & LM & LM & LM \\
\hline May (vd) & ST & ST & LM & LM & LM & ST & LM & LM & ST & LM & LM & LM & LM \\
\hline $\operatorname{Jun}(\mathrm{m})$ & LM & LM & LMST & $\mathrm{LM}$ & LM & LM & ST & LM & LM & LM & LM & LM & LM \\
\hline Jun (d) & LM & LM & LM & LM & LM & LM & LM & LM & LM & LM & LM & LM & LM \\
\hline Jun (vd) & $\mathrm{ST}$ & $\mathrm{ST}$ & LM & $\mathrm{ST}$ & LM & $\mathrm{ST}$ & ST & ST & ST & LM & LM & LM & LM \\
\hline $\mathrm{Jul}(\mathrm{m})$ & LM & LM & ST & LM & LM & LM & ST & LM & LM & LM & LM & ST & LM \\
\hline Jul (d) & LM & LM & LM & LM & LM & LM & LM & LM & LM & LM & LM & LM & LM \\
\hline Jul (vd) & LM & LM & LM & LM & LM & ST & ST & ST & ST & ST & LM & ST & LM \\
\hline $\operatorname{Aug}(\mathrm{m})$ & LM & LM & LM & LM & LM & LM & LM & LM & LM & LM & LM & LM & LM \\
\hline Aug (d) & LM & LM & LM & LM & LM & LM & $\mathrm{LM}$ & LM & $\mathrm{ST}$ & ST & LM & LM & LM \\
\hline Aug (vd) & LM & ST & LM & ST & ST & ST & ST & LM & ST & ST & LM & ST & LM \\
\hline $\operatorname{Sep}(\mathrm{m})$ & LM & ST & LM & ST & ST & ST & ST & $\mathrm{ST}$ & LM & LM & $\mathrm{ST}$ & ST & LM \\
\hline $\operatorname{Sep}(\mathrm{d})$ & LM & LM & LM & LM & LM & LM & LM & LM & LM & LM & LM & LM & LM \\
\hline Sep (vd) & LM & ST & LM & ST & LM & ST & ST & ST & ST & LM & LM & LM & LM \\
\hline Oct (m) & LM & ST & LM & ST & ST & ST & ST & ST & ST & LM & ST & LM & LM \\
\hline Oct (d) & LM & LM & LM & LM & LM & ST & ST & LM & LM & LM & LM & LM & LM \\
\hline Oct (vd) & LM & LM & LM & LM & LM & LM & LM & LM & LM & LM & LM & $\mathrm{ST}$ & LM \\
\hline Nov (m) & LM & LM & LM & LM & LM & ST & ST_QRV & LM & LM & LM & LM & LM & LM \\
\hline Nov (d) & LM & LM & LM & LM & LM & ST & ST_QRV & ST & QRV & LM & LM & LM & LM \\
\hline Nov (vd) & ST_QRV & LM & LM & LM & LM & QRV & ST_QRV & LM & ST_QRV & LM & LM & ST & ST \\
\hline $\operatorname{Dec}(\mathrm{m})$ & LM & LM & LM & QRV & LM & ST & ST_QRV & ST & LM & LMQRV & LM & LM & LM \\
\hline $\operatorname{Dec}(\mathrm{d})$ & QRV & ST & ST & ST & ST & ST & ST_QRV & ST & ST & ST & ST & ST & LM \\
\hline $\operatorname{Dec}(\mathrm{vd})$ & QRV & LM & LM & LM & LM & ST & $* * *$ & LM & LM & LM & LM & LM & LM \\
\hline
\end{tabular}

In the equinoctial months, the performance of STORM_foF2 MED,IRI is always considerably better than IFELM whatever the level of geomagnetic activity: under moderate geomagnetic conditions, the forecasts provided by

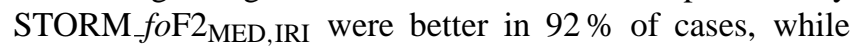
IFELM perform better in only $8 \%$ of the cases examined; under disturbed and very disturbed geomagnetic situations the performance of STORM $f o$ F $2_{\text {MED,IRI }}$ is better in $67 \%$ of the cases investigated, while the performance of IFELM is superior in only $33 \%$ of the cases analysed.
In the summer months the IFELM perform much better than STORM $f o{ }_{0} 2_{\text {MED,IRI }}$ under moderate geomagnetic activity (IFELM predictions were better in $75 \%$ of cases, while STORM $f_{o} \mathrm{~F}_{2 \mathrm{MED} \text {,IRI }}$ predictions were better in $25 \%$ of the cases investigated) and under disturbed geomagnetic activity (IFELM predictions were better in $92 \%$ of cases, while STORM $f o$ F2 ${ }_{\text {MED,IRI }}$ predictions were better in $8 \%$ of the cases analysed). In contrast, the performance of

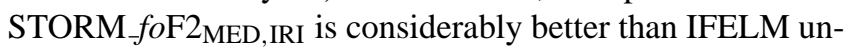
der very disturbed geomagnetic activity (IFELM predictions were better in $25 \%$ of cases, while STORM $f o$ F $2_{\text {MED,IRI }}$ predictions were better in $75 \%$ of the cases investigated). 
Table 4. The cases in which it is possible to consider the different local models simultaneously operative (indicated with LM) for forecasting foF2 over the European area are shown for each month under moderate (m), disturbed (d), and very disturbed (vd) geomagnetic conditions. The number of IFELM sites operating simultaneously in the western, central and eastern part of the European area under consideration, are shown in red in the columns (W), (C), and (E) respectively. The empty cells indicate cases that were discarded because the performance of IFELM was worse than that of STORM $f o F 2$ MED,IRI. The values in the last column indicate the total number of IFELM sites operating at the same time.

\begin{tabular}{|c|c|c|c|c|c|c|c|c|c|c|c|c|c|c|c|c|c|}
\hline Month & Tor & Poi & Lan & Dou & Slo & Rom & Pru & Jul & Kal & Upp & Lyc & Sod & Kir & W & $\mathrm{C}$ & $\mathrm{E}$ & $\mathrm{T}$ \\
\hline $\operatorname{Jan}(\mathrm{m})$ & LM & LM & LM & & LM & & & LM & LM & LM & & LM & LM & 4 & 1 & 4 & 9 \\
\hline $\operatorname{Jan}(\mathrm{d})$ & LM & LM & LM & & LM & & & LM & & LM & & LM & LM & 4 & 1 & 3 & 8 \\
\hline Jan (vd) & & & LM & LM & & LM & LM & LM & LM & LM & & LM & LM & 2 & 3 & 4 & 9 \\
\hline Feb (m) & & & & & LM & & & & & LM & & & LM & 1 & & 2 & 3 \\
\hline Feb (d) & & LM & LM & LM & LM & & & & LM & LM & LM & LM & LM & 4 & & 5 & 9 \\
\hline Feb (vd) & & LM & LM & LM & LM & & LM & & LM & LM & & LM & & 4 & 1 & 3 & 8 \\
\hline $\operatorname{Mar}(\mathrm{m})$ & LM & & LM & LM & LM & LM & & & LM & LM & & LM & & 4 & 1 & 3 & 8 \\
\hline $\operatorname{Mar}(d)$ & LM & LM & LM & & LM & & & & & & LM & LM & & 4 & & 2 & 6 \\
\hline Mar (vd) & & LM & & & & LM & & & & & LM & LM & LM & 1 & 1 & 3 & 5 \\
\hline Apr (m) & LM & & LM & & & & & & & & & & LM & 2 & & 1 & 3 \\
\hline Apr (d) & LM & LM & & & LM & & & & LM & LM & & & & 3 & & 2 & 5 \\
\hline Apr (vd) & & LM & LM & LM & LM & & & & LM & LM & LM & LM & LM & 4 & & 5 & 9 \\
\hline May (m) & & & LM & & LM & & LM & LM & LM & LM & LM & & & 2 & 2 & 3 & 7 \\
\hline May (d) & LM & & LM & LM & LM & & LM & LM & LM & LM & LM & LM & LM & 4 & 2 & 5 & 11 \\
\hline May (vd) & & & LM & LM & LM & & LM & LM & & LM & LM & LM & LM & 3 & 2 & 4 & 9 \\
\hline Jun (m) & LM & LM & & LM & LM & LM & & LM & LM & LM & LM & LM & LM & 4 & 2 & 5 & 11 \\
\hline Jun (d) & LM & LM & LM & LM & LM & LM & LM & LM & LM & LM & LM & LM & LM & 5 & 3 & 5 & 13 \\
\hline Jun (vd) & & & LM & & LM & & & & & LM & LM & LM & LM & 2 & & 4 & 6 \\
\hline Jul (m) & LM & LM & & LM & LM & LM & & LM & LM & LM & LM & & LM & 4 & 2 & 4 & 10 \\
\hline Jul (d) & LM & LM & LM & $\mathrm{LM}$ & LM & LM & LM & LM & LM & LM & LM & LM & LM & 5 & 3 & 5 & 13 \\
\hline Jul (vd) & LM & LM & LM & LM & LM & & & & & & LM & & LM & 5 & & 2 & 7 \\
\hline Aug (m) & LM & LM & LM & LM & LM & LM & LM & LM & LM & LM & LM & LM & LM & 5 & 3 & 5 & 13 \\
\hline Aug (d) & LM & LM & LM & LM & LM & LM & LM & LM & & & LM & LM & LM & 5 & 3 & 3 & 11 \\
\hline Aug (vd) & LM & & LM & & & & & LM & & & LM & & LM & 2 & 1 & 2 & 5 \\
\hline $\operatorname{Sep}(\mathrm{m})$ & LM & & LM & & & & & & LM & LM & & & LM & 2 & & 3 & 5 \\
\hline Sep (d) & LM & LM & LM & LM & LM & LM & LM & LM & LM & LM & LM & LM & LM & 5 & 3 & 5 & 13 \\
\hline Sep (vd) & LM & & LM & & LM & & & & & LM & LM & LM & LM & 3 & & 4 & 7 \\
\hline Oct (m) & LM & & LM & & & & & & & LM & & LM & LM & 2 & & 3 & 5 \\
\hline Oct (d) & LM & LM & LM & LM & LM & & & LM & LM & LM & LM & LM & LM & 5 & 1 & 5 & 11 \\
\hline Oct (vd) & LM & LM & LM & LM & LM & LM & LM & LM & LM & LM & LM & & LM & 5 & 3 & 4 & 12 \\
\hline Nov (m) & LM & LM & LM & LM & LM & & & LM & LM & LM & LM & LM & LM & 5 & 1 & 5 & 11 \\
\hline Nov (d) & LM & LM & LM & LM & LM & & & & & LM & LM & LM & LM & 5 & & 4 & 9 \\
\hline Nov (vd) & & LM & LM & LM & LM & & & LM & & LM & LM & & & 4 & 1 & 2 & 7 \\
\hline $\operatorname{Dec}(\mathrm{m})$ & LM & LM & LM & & LM & & & & LM & & LM & LM & LM & 4 & & 4 & 8 \\
\hline $\operatorname{Dec}(d)$ & & & & & & & & & & & & & LM & & & & 1 \\
\hline Dec (vd) & & LM & LM & LM & LM & & & LM & LM & LM & LM & LM & LM & 4 & 1 & 5 & 10 \\
\hline
\end{tabular}

Regarding the eastern part of the area (including the stations of Kaliningrad, Uppsala, Lyckesele, Sodankyla, and Kiruna), extending in latitude from $57^{\circ} .7^{\prime} \mathrm{N}$ to $67^{\circ} .8^{\prime} \mathrm{N}$ and in longitude from $17^{\circ} .6^{\prime} \mathrm{E}$ to $26^{\circ} .6^{\prime} \mathrm{E}$, the IFELM perform much better than STORM $f o$ F2 2 MED,IRI. In this zone, the predictions of IFELM were better in $72 \%$ of cases, while those of STORM $f o$ F 2 MED,IRI were better in only $26 \%$ of the cases analysed.

In the winter months, the IFELM perform much better than STORM $f o$ F $2_{\text {MED,IRI, }}$, both under moderate geomag- netic conditions (IFELM predictions were better in $75 \%$ of

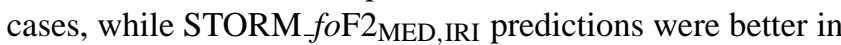
$15 \%$ of the cases investigated), and under very disturbed geomagnetic conditions (IFELM predictions were better in $70 \%$ of cases, while STORM $f o$ F2 MED,IRI predictions were better in $25 \%$ of the cases examined). Under disturbed geomagnetic activity, the IFELM again performed better than $\mathrm{STORM}_{f} f o \mathrm{~F} 2_{\mathrm{MED}, \text { IRI }}$ providing predictions better in $65 \%$ of cases while $\mathrm{STORM}_{-} f o \mathrm{~F} 2_{\mathrm{MED}, \text { IRI }}$ predictions were better in $30 \%$ of the cases analysed. 

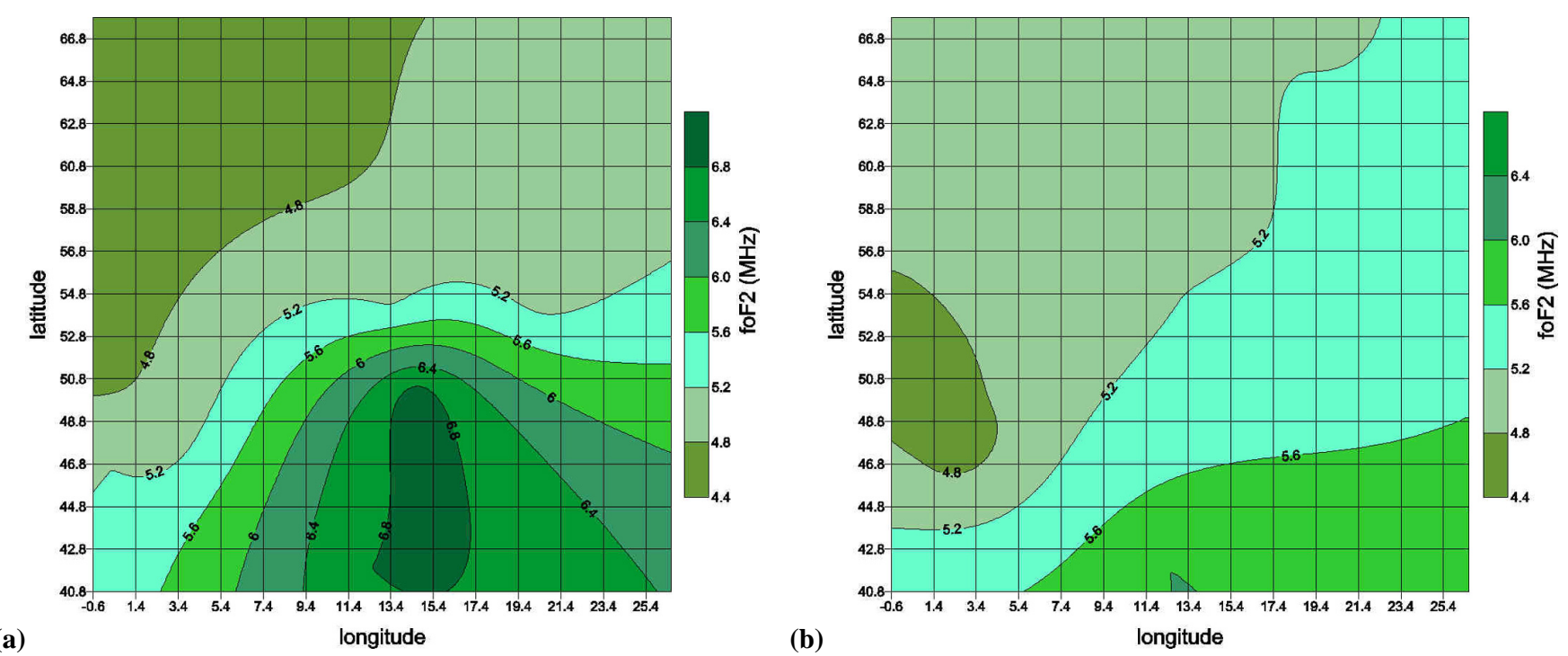

Fig. 2. (a) Map obtained from $f_{o} \mathrm{~F} 2$ measurements and (b) forecasting map for $f o \mathrm{~F} 2$ two hours in advance generated using the IFERM model on 8 August 1991 at 05:00 UT under moderate geomagnetic conditions $(\operatorname{ap}(\tau=0.8)=14.37 ; \operatorname{ap}(\tau=0.9)=15.6)$.
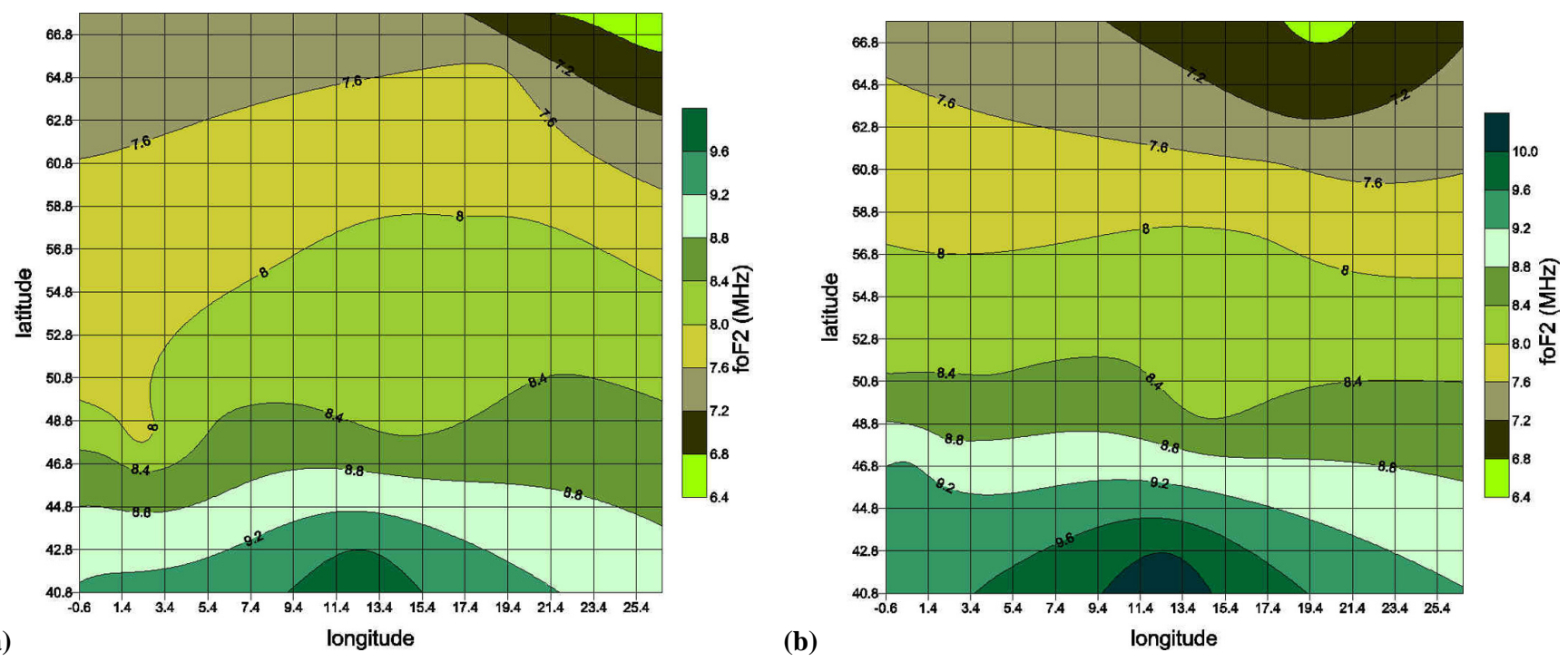

Fig. 3. (a) Map obtained from $f o F 2$ measurements and (b) forecasting map for $f o F 2$ one hour in advance generated using the IFERM model on 11 September 1991 at 13:00 UT under disturbed geomagnetic conditions $(\operatorname{ap}(\tau=0.8)=26.3 ; \operatorname{ap}(\tau=0.9)=27)$.

In the equinoctial months, under moderate geomagnetic conditions, the IFELM and the STORM $f o F 2_{\mathrm{MED} \text {,IRI model }}$ provided exactly the same performance (better predictions in $50 \%$ of cases with both models). IFELM performed much better than STORM_foF2 MED,IRI, both under disturbed geomagnetic activity (IFELM predictions were better in $70 \%$ of cases, while $\mathrm{STORM}_{-} f o \mathrm{~F}_{\mathrm{MED} \text {,IRI }}$ predictions were better in $30 \%$ of the cases investigated), and very disturbed geomagnetic activity (IFELM predictions were better in $80 \%$ of cases, while STORM $f o$ F 2 MED,IRI predictions were better in $20 \%$ of the cases investigated).
In the summer months the performance of IFELM is far better than STORM $f o$ F2 2 MED,IRI, both under moderate geomagnetic activity (IFELM predictions were better in $85 \%$ of cases, while STORM $f o F 2_{\text {MED, IRI }}$ predictions were better in $15 \%$ of the cases investigated), and under disturbed geomagnetic activity (IFELM predictions were better in $90 \%$

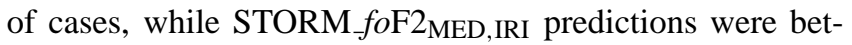
ter in $10 \%$ of the cases analysed). Under very disturbed geomagnetic activity, IFELM performed slightly better than STORM $f o$ F2 2 MED,IRI (IFELM predictions were better in $60 \%$ of cases, while STORM_foF $2_{\mathrm{MED}, \text { IRI }}$ predictions were better in $40 \%$ of the cases investigated). 

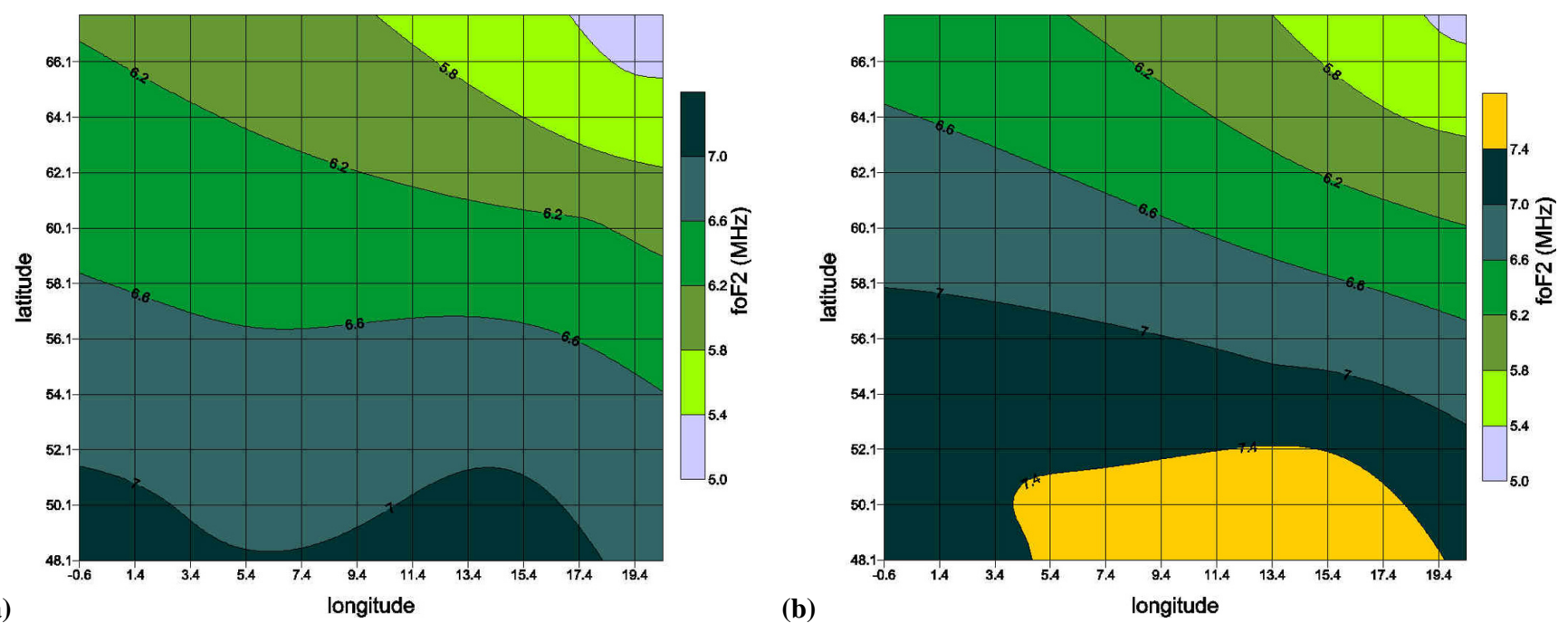

Fig. 4. (a) Map obtained from $f o \mathrm{~F} 2$ measurements and (b) forecasting map for $f o \mathrm{~F} 2$ three hour in advance generated using the IFERM model on 2 May 1991 at 15:00 UT under very disturbed geomagnetic conditions $(\operatorname{ap}(\tau=0.8)=45.3 ; \operatorname{ap}(\tau=0.9)=33.8)$.

It should be noted that the forecasts generated by the quiet time reference values were only very rarely better than the other models as was expected considering that all the periods analysed were to some extent disturbed. This is a confirmation of the reliability of the $f o \mathrm{~F} 2 \mathrm{QT}$ values calculated for each local station and on which the ionospheric forecasting is based (Eq. 2).

Furthermore, the STORM $f o \mathrm{~F} 2_{\mathrm{QT}}$ model predictions are almost always worse than those of the $\mathrm{STORM}_{-} f o \mathrm{~F} 2_{\mathrm{MED}, \mathrm{IRI}}$ model. STORM_foF2 $2_{\mathrm{QT}}$ performs better than STORM $f o$ F2 MED,IRI in only $11 \%$ of the cases analysed under very disturbed geomagnetic conditions (percentages slightly higher than $11 \%$ were found under moderate and disturbed geomagnetic conditions).

This occurs because the monthly medians are not representative of quiet time reference values but instead refer to a moderately disturbed ionosphere (Wrenn et al., 1987). Therefore, when at a given epoch the same scaling factor is used to scale both the monthly median value and the quiettime reference value, the $\mathrm{STORM}_{-} f o \mathrm{~F} 2_{\mathrm{MED}, \text { IRI }}$ model inevitably provides a prediction of $f o \mathrm{~F} 2$ "closer" to the value of $f o \mathrm{~F} 2$ (measured under non quiet geomagnetic conditions), than the prediction provided by STORM $f o \mathrm{~F} 22_{\mathrm{QT}}$.

Figures $2 \mathrm{a}, 3 \mathrm{a}$, and $4 \mathrm{a}$ show the maps of $f o \mathrm{~F} 2$ obtained from the $f o \mathrm{~F} 2$ measurements. Figures $2 \mathrm{~b}, 3 \mathrm{~b}$, and $4 \mathrm{~b}$ show the corresponding forecasting maps for $f o \mathrm{~F} 2$ obtained with the $f o \mathrm{~F} 2$ values predicted in the $N$ IFELM operating simultaneously.

The cells of these maps $\left(2^{\circ} \times 2^{\circ}\right)$ were carefully analysed to assess IFERM performance on the spatial regional scale.

Under moderate geomagnetic activity (Fig. 2a-b), it emerged that there is a zone extending in latitude approximately from $40^{\circ} .8^{\prime} \mathrm{N}$ to $46^{\circ} .8^{\prime} \mathrm{N}$ and in longitude from $13^{\circ} .4^{\prime} \mathrm{E}$ to $17^{\circ} .4^{\prime} \mathrm{E}$, where the comparison between the map obtained with the $f o \mathrm{~F} 2$ measurements, and the forecasting map generated by IFERM have $f o \mathrm{~F} 2$ values that differ by no more than $1.6 \mathrm{MHz}$. In the same zone of latitude, but in the two sectors extending in longitude approximately from $9^{\circ} .4^{\prime} \mathrm{E}$ to $13^{\circ} .4^{\prime} \mathrm{E}$ and from $17^{\circ} .4^{\prime} \mathrm{E}$ to $25^{\circ} .4^{\prime} \mathrm{E}$ the situation is somewhat better with a difference no greater than $1.2 \mathrm{MHz}$; at middle-high and high latitudes, in a relatively large area, extending in latitude from about $52^{\circ} \mathrm{N}$ to $67^{\circ} .4^{\prime} \mathrm{N}$ and in longitude from $-0^{\circ} .6^{\prime} \mathrm{W}$ to $26^{\circ} .6^{\prime} \mathrm{E}$, the IFERM performance can be considered satisfactory because the differences between the $f o \mathrm{~F} 2$ values on the map of $f o \mathrm{~F} 2$ measurements, and those indicated on the map generated by IFERM, differ by no more than $0.4 \mathrm{MHz}$ (in the central part) and $0.8 \mathrm{MHz}$ (in the eastern and western parts).

Under disturbed geomagnetic conditions (Fig. 3a-b), the comparison between the map obtained with the $f o \mathrm{~F} 2$ measurements and the forecasting map generated by IFERM is very favourable over the entire geographic area under consideration. It emerged that in the region extending in latitude from $46^{\circ} .8^{\prime} \mathrm{N}$ to $67^{\circ} .8^{\prime} \mathrm{N}$ and in longitude from $-0^{\circ} .6^{\prime} \mathrm{W}$ to $26^{\circ} .6^{\prime} \mathrm{E}$, large sectors can be distinguished where the differences between $f o \mathrm{~F} 2$ measurements and $f o \mathrm{~F} 2$ predictions are no greater than $0.4 \mathrm{MHz}$, moreover at lower latitudes, in the region between $40^{\circ} .8^{\prime} \mathrm{N}$ and $46^{\circ} .8^{\prime} \mathrm{N}$, IFERM performance is still very good with these differences no greater than $0.8 \mathrm{MHz}$.

Also under very disturbed geomagnetic conditions (Fig. 4a-b) the comparison between the map of the foF 2 measurements and the forecasting map generated by IFERM can be considered satisfactory over a relatively large area, extending in latitude from about $52^{\circ} \mathrm{N}$ to $67^{\circ} .4^{\prime} \mathrm{N}$ and in longitude from $-0^{\circ} .6^{\prime} \mathrm{W}$ and $20^{\circ} .6^{\prime} \mathrm{E}$. In this area small sectors can be identified where the differences between $f o \mathrm{~F} 2$ measurements and $f o \mathrm{~F} 2$ predictions are no greater than $0.4 \mathrm{MHz}$ 
and broader sectors where these differences are no greater than $0.8 \mathrm{MHz}$. The performance of IFERM deteriorates slightly at lower latitudes, in particular in the zone extending in latitude from $48^{\circ} \cdot 1^{\prime} \mathrm{N}$ to $52^{\circ} \mathrm{N}$ and in longitude from $4^{\circ} .4^{\prime} \mathrm{E}$ to $11^{\circ} .4^{\prime} \mathrm{E}$, where the differences between the $f o \mathrm{~F} 2$ measurements and the $f o \mathrm{~F} 2$ forecasts are no greater than $1.2 \mathrm{MHz}$.

The quiet-time values of $f o \mathrm{~F} 2$ can easily be calculated at least 1 day ahead for all $24 \mathrm{~h}$ following the procedure described in Pietrella and Perrone (2008). The forecasting algorithm (Eq. 2) depends on the geomagnetic index ap and this can easily be derived from the $\mathrm{Kp}$ index, which is predicted for $3 \mathrm{~h}$ ahead (see http://www.swpc.noaa.gov/wingkp/ wingkp_list.txt). Consequently each local model can provide short-term $f o \mathrm{~F} 2$ predictions up to $3 \mathrm{~h}$ in advance.

As regards the prediction of geomagnetic activity, many algorithms have been developed. For example, linear prediction filters have been applied for self-predicting the Ap index (Thomson et al., 1993) and some improvements in prediction accuracy were achieved using a neural network algorithm (Thomson, 1993). Nevertheless, a few studies carried out to verify the forecasting accuracy have shown that, especially in disturbed conditions, geomagnetic index prediction tend to be disappointing (Joselyn, 1995). This probably occurs because the forecasting techniques do not include an appropriate knowledge of the solar phenomena and magnetospheric influences that cause the geomagnetic activity. However, it might be hoped that in the future the prediction of geomagnetic activity based on observations of solar phenomena and above all the use in real time of near-Earth observations of the approaching solar wind (nowcasting) might considerably improve geomagnetic activity forecasting and as a consequence the performance of IFELM.

Even if a local geomagnetic activity index would be preferable for better "capturing" local storm effects and so increase the capability of each local model to provide more reliable predictions, the tests carried out to evaluate the performance of all the IFELM results revealed that the $f o \mathrm{~F} 2$ forecasts provided by the various ionospheric stations must be considered very satisfactory when compared with the forecasts generated by the STORM model (Table 3). This means that the 13 IFELM results, as a whole, can constitute the result of the ionospheric forecasting empirical regional model (IFERM) which can be used for short term forecasting of $f o \mathrm{~F} 2$ up to $3 \mathrm{~h}$ ahead in the European area, on the basis of $f o \mathrm{~F} 2$ predictions produced by those stations that can be considered as simultaneously operative (Table 4).

Table 4 shows that, excluding the month of August under moderate geomagnetic conditions, and the months of June, July, September under disturbed geomagnetic conditions, it is never possible to use all the 13 IFELM simultaneously. Nevertheless, the strength of IFERM lies in the fact that it is almost always possible, even excluding certain IFELM, that a specific number $N<13$ of IFELM can still adequately cover the area under investigation providing simultaneous predictions of $f o \mathrm{~F} 2$.

For example, in June under moderate geomagnetic conditions, IFERM might work with $N=11$ stations excluding the local models at the stations of Lannion and Pruhonice; in January under disturbed geomagnetic conditions, the number of stations utilized by IFERM to generate $f o \mathrm{~F} 2$ forecasts would be $N=8$; in October under very disturbed geomagnetic conditions, IFERM might work with $N=12$ stations with Sodankyla the only inoperative station.

Table 4 shows 14 cases in which IFERM could not rely on the stations at Rome, Pruhonice, and Juliusruh for $f o \mathrm{~F} 2$ forecasting (Table 4, column C).

However, in all these cases, there are still enough IFELM operating simultaneously both in the eastern part (Table 4, column E) and in the western part of the area under consideration (Table 4, column W), so that an appropriate interpolation between the values of $f o \mathrm{~F} 2$ predicted by the IFELM located in the eastern and western parts of Europe can generate $f o \mathrm{~F} 2$ values at the stations of the central area.

In the particular case of December under disturbed geomagnetic conditions, only the local model at Kiruna can be considered as operative, and so interpolation can not be used to calculate predicted values of $f o \mathrm{~F} 2$ at the other stations on the basis of $f o \mathrm{~F} 2$ values provided by the Kiruna station alone. In this single case IFERM is not capable of providing $f o \mathrm{~F} 2$ forecasts for the European area.

In general, when $M$ stations are excluded, the $f o \mathrm{~F} 2$ values are forecast in the remaining $(N-M)$ workstations.

Based on the predicted values of $f o \mathrm{~F} 2$ at a given epoch by the $(N-M)$ IFELM, it is then possible, considering the European area as a grid of equi-spaced points in latitude and longitude, also to calculate the values of $f o \mathrm{~F} 2$ at the $M$ ionospheric stations that were initially discarded, along with the values of $f o \mathrm{~F} 2$ at each grid point by means of an appropriate interpolation algorithm, thus obtaining a short-term forecast map of $f o \mathrm{~F} 2$ at that epoch.

Regarding at least for the three $f o \mathrm{~F} 2$ forecasting maps analysed (Figs. 2-4), at middle latitudes in the central part of the area under consideration, the performance of IFERM does not produce good results. Nevertheless, the forecasting maps generated by IFERM show very large areas located at middle-high and high latitudes where the $f o \mathrm{~F} 2$ predictions quite faithfully match the $f o \mathrm{~F} 2$ measurements. This can be considered a very satisfactory result because it is not easy to provide reliable $f o \mathrm{~F} 2$ predictions during geomagnetic storms, especially at high latitudes.

Therefore, with regard to future developments, IFERM could be used to generate short-term $f o \mathrm{~F} 2$ forecast maps up to $3 \mathrm{~h}$ in advance over the European area that includes the 13 ionospheric observatories considered.

Moreover, the development of other local models which are able to provide a short-term forecasting of M3000F2 in the same area considered in this study, could constitute a further empirical model for the regional forecasting of 
M3000F2, which could be used in connection with IFERM to produce short term predictions of $f o \mathrm{~F} 2$ and $\mathrm{M} 3000 \mathrm{~F} 2$ at a given epoch over the European area under consideration. The value pairs of $f o \mathrm{~F} 2$ and $\mathrm{M} 3000$ thus predicted, could be used as input to the IRI model to generate short term forecasting of 3-D matrices of electron density following a technique already adopted for obtaining nowcasting maps of electron density in the Mediterranean area (Pezzopane et al., 2011).

The achievement of short-term $f o \mathrm{~F} 2$ forecast maps together with 3-D matrices of electron density for a few hours ahead in the European area is the goal in the future.

Acknowledgements. The author is grateful to the unknown referee and to A. Danilov for their suggestions that contributed to improving the paper. The author would like also to thank S. Spadoni for her assistance in producing the maps of $f o \mathrm{~F} 2$.

Topical Editor P.-L. Blelly thanks A. Danilov and another anonymous referee for their help in evaluating this paper.

\section{References}

Araujo-Pradere, E. A., Fuller-Rowell, T. J., and Codrescu, M. V.: STORM: an empirical storm-time ionospheric correction model 1. Model description, Radio Sci., 37, RS1070, doi:10.1029/2001RS002467, 2002.

Belehaki, A., Moraitis, G., and Tsagouri, I.: On the derivation of an hourly local index to define the normal ionosphere, Annali di Geofisica, 43, 189-203, 2000.

Bilitza, D.: IRI 2000, Radio Sci., 36, 261-276, doi:10.1029/2000RS002432, 2001.

Bilitza, D. and Reinisch, B. W.: International Reference Ionosphere 2007: Improvements and new parameters, Adv. Space Res., 42, 599-609, doi:10.1016/j.asr.2007.07.048, 2008.

Bradley, P.: PRIME (Prediction and Retrospective Ionospheric Modelling over Europe), Cost Action 238, Final Report, Rutherford Appleton Laboratory, Chilton Didcot, UK, 1999.

Buonsanto, M. J.: Ionospheric Storms - A review, Space Sci. Rev., 88, 563-601, 1999.

Burns, A. G. and Killen, T. L.: The equatorial neutral thermospheric response to geomagnetic forcing, Geophys. Res. Lett., 19, 977980, 1992.

Cander, Lj. R. and Mihajlovic, S. J.: Forecasting ionospheric structure during the great geomagnetic storms, J. Geophys. Res., 103, 391-398, doi:10.1029/97JA02418, 1998.

Cander, Lj. R., Milosavljevic, M. M., Stankovic, S. S., and Tomasevic, S.: Ionospheric forecasting technique by artificial neural network, Electronics Lett., 34, 1573-1574, 1998.

Comite Consultatif International des Radio Communications (CCIR): Atlas of ionospheric characteristics, Rep 340-6 Geneva, 1991.

Cooper, J., Barbatsi, K., Gulyaeva, T. L., Moraitis, G. A., Spoelstra, T. A. Th., Stanislawska, I., Radicella, S. M., and Zhang, M. L.: PRIME Catalogue of undisturbed days No. 1 in proceedings of COST 238 Workshop, Universitat Graz, Austria, Part 1, 1993.

Fuller-Rowell, T. J., Codrescu, M. V., Roble, R. G., and Richmond, A. D.: How does the thermosphere and ionosphere react to a geomagnetic storm?, in: Magnetic Storms, edited by: Tsurutani, B. T., Gonzales, W. D., Kamide, Y., and Arballo, J. K., Geophys- ical Monograph 98, American Geophysical Union, Washington, D.C., 1997.

Hanbaba, R.: Improved quality of services ionospheric telecommunication systems planning and operation, Cost Action 251, Final Report, Published by Space Research Centre,Warsaw, Poland, 1999.

Hocke, K. and Schlegel, K.: A review of atmospheric gravity waves and travelling ionospheric disturbances: 1982-1995, Ann. Geophys., 14, 917-940, doi:10.1007/s00585-996-0917-6, 1996.

International Telecommunication Union (ITU): ITU-R reference ionospheric characteristics and methods for basic MUF, operational MUF and ray-paths predictions, Recommendation ITU-R P. 1239, Geneva, 1997.

IPS-Radio and Space Services: ASAPS V6, available at: http: //www.ips.gov.au/Products_and_Services/1/1, undated, last accessed November 2011.

Jones, W. B. and Gallet, R. M.: Representation of diurnal and geographical variation of ionospheric data by numerical methods, Telecommun. J., 29, 129-149, 1962.

Joselyn, J. A.: Geomagnetic activity forecasting; the state of the art, Rev. Geophys., 33, 383-401, 1995.

Kouris, S. S. and Fotiadis, D. N.: Ionospheric variability: a comparative statistical study, Adv. Space Res., 29, 977-985, 2002.

Kozin, I. D., Kozin, V. I., and Fedulina, I. N.: On a choice of the ionospheric disturbance indices, Geomagn. Aeron., 35, 111-112, 1995.

Mendillo, M.: A study of the relationship between geomagnetic storms and ionospheric disturbances at mid-latitudes, Planet. Space. Sci., 21, 349-358, 1973.

Muhtarov, P. and Kutiev, I.: Autocorrelation method for temporal interpolation and short-term prediction of ionospheric data, Radio Sci., 34, 459-464, 1999.

Oyeyemi, E. O., Poole, A. W. V., and McKinnell, L. A.: On the global short-term forecasting of the ionospheric critical frequency foF2 up to 5 hours in advance using neural networks, Radio Sci., 40, RS6012, doi:10.1029/2004RS003239, 2005.

Perrone, L., De Franceschi, G., and Gulyaeva, T. L.: The timeweighted magnetic indices $\operatorname{ap}(\tau), \operatorname{PC}(\tau), \operatorname{AE}(\tau)$ and their correlation to the southern high latitude ionosphere, Phys. Chem. Earth (C), 26, 331-334, 2001.

Pezzopane, M., Pietrella, M., Pignatelli, A., Zolesi, B., and Cander, Lj. R.: Assimilation of autoscaled data and regional and local ionospheric models as input sources for a real-time 3-D International Reference Ionosphere modelling, Radio Sci., 46, RS5009, doi:10.1029/2011RS004697, 2011.

Pietrella, M. and Perrone, L.: Instantaneous Space Weighted Ionospheric Regional Model for instantaneous mapping of the critical frequency of the F2 layer in the European region, Radio Sci., 40, RS1005, doi:10.1029/2003RS003008, 2005.

Pietrella, M. and Perrone, L.: A local ionospheric model for forecasting the critical frequency of the F2 layer during disturbed geomagnetic and ionospheric conditions, Ann. Geophys., 26, 323334, doi:10.5194/angeo-26-323-2008, 2008.

Pietrella, M., Bianchi, C., and Scotto, C.: Electronic density contours and gravity waves, Il Nuovo Cimento, 20 C, 609-612, 1997.

Pietrella, M., Perrone, L., Fontana, G., Romano, V., Malagnini, A., Tutone, G., Zolesi, B., Cander, Lj. R., Belehaki, A., Tsagouri, I., Kouris, S. S., Vallianatos, F., Makris, J., and Angling, M.: 
Oblique-incidence ionospheric soundings over Central Europe and their application for testing now casting and long term prediction models, Adv. Space Res., 43, 1611-1620, 2009.

Prölss, G. W.: Ionospheric F region storms, in: Handbook of atmospheric electrodynamics, 2, edited by: Volland, H., CRC Press, Boca Raton, 195-248, 1995.

Prölss, G. W.: Magnetic storm associated perturbations of the upper atmosphere, in: Magnetic Storms, Geophysical Monograph 98, edited by: Tsurutani, B. T., Gonzales, W. D., Kamide, Y., and Arballo, J. K., American Geophysical Union, Washington, D.C., 1997.

Richmond, A. D. and Matsushita, S.: Thermospheric response to a magnetic substorm, J. Geophys. Res., 80, 2839-2850, 1975.

Rishbeth, H., Fuller-Rowell, T. J., and Rees, D.: Diffusive equilibrium and vertical motion in the thermosphere during a severe magnetic storm: a computational study, Planet. Space Sci., 35, 1157-1165, 1987.

Roble, R. G., Richmond, A. D., Oliver, W. L., and Harper, R. M.: Ionospheric effects of the gravity wave launched by the September 18, 1974, Sudden Commencement, J. Geophys. Res., 83, 999-1009, 1978.

Stewart, F. G.: ICEPAC-Technical Manual, available at: http:// www.greg-hand.com/manuals/icepac_tech_manual.pdf, undated, last access date: February 2009.

Testud, J.: Gravity waves generated during magnetic substorm, J. Atmos. Terr. Sci., 32, 1793-1805, 1970.

Titheridge, J. E.: Non periodic irregularities in the ionosphere, J. Geophys. Res., 76, 6955-6960, 1971.
Thomson, A. W. P.: Neural networks and non-linear prediction of geomagnetic activity, in: Proceedings of the 1993 International Workshop on Artificial Intelligence Applications in Solar Terrestrial Physics, 133 p., 1993.

Thomson, A. W. P., Clark, T. D. G., and Kerridge, D. J.: Forecasting Ap in the short-term using time series analysis, in: Proceedings of the 1992 Solar-Terrestrial Predictions Workshop, 3, 269 p., 1993.

Wrenn, G. L.: Time-Weighted accumulations $\operatorname{ap}(\tau)$ and $\operatorname{Kp}(\tau)$, J. Geophys. Res., 92, 10125-10129, 1987.

Wrenn, G. L. and Rodger, A. S.: Geomagnetic modification of the mid-latitude ionosphere: toward a strategy for the improved forecasting of foF2, Radio Sci., 24, 99-111, 1989.

Wrenn, G. L., Rodger, A. S., and Rishbeth, H.: Geomagnetic storms in Antarctic F region. I. Diurnal and seasonal patterns in main phase effects, J. Atmos. Terr. Phys., 49, 901-913, 1987.

Zolesi, B. and Cander, Lj. R.: Advances in regional ionospheric mapping over Europe, Ann. Geofis., 41, 827-842, 1998.

Zolesi, B., Belehaki, A., Tsagouri, I., and Cander, Lj. R.: Real-time updating of the Simplified Ionospheric Regional Model for operational applications, Radio Sci., 39, RS2011, doi:10.1029/2003RS002936, 2004.

Zolesi, B., Fontana, G., Perrone, L., Pietrella, M., Romano, V., Tutone, G., Belehaki, A., Tsagouri, I., Kouris, S. S., Vallianatos, F., Makris, J. P., and Angling, M. J.: A new campaign for obliqueincidence ionospheric sounding over Europe and its data application, J. Atmos. Terr. Phys., 70, 854-865, 2008. 